\section{High Added Value - but Many Stumbling Blocks along the Way NTN Biotech Identifies where the Shoe Pinches}

Elsbeth Heinzelmann, Journalist science + technology

Abstract: The year 1958, when DNA was first made in a test tube, marked the birth of modern biotechnology. DNA has now developed into an important technology that makes a key contribution in various sectors such as agriculture, environment and cleansing, and it has triggered a veritable boom in medicine. Today, biologics account for more than $60 \%$ of newly approved drugs. They are efficient, save time and money and have few or minimal side effects, fuelling the appetite of big pharma to take over biotech companies. Where will the journey lead?

Keywords: Antibiotics · Biotechnology · DNA

\section{How to Reduce Health Costs and Boost Productivity}

In order to control R\&D costs and boost productivity, drug developers try to improve clinical study performance and develop cost-effective therapies to reduce health care spending, according to Outlook 2015 issued by the Tufts Center for the Study of Drug Development in Boston. "The key challenge for drug sponsors, policy makers and payers is to balance the need for new, innovative medicines with the equally pressing need to bring health care spending under control", comments Tufts CSDD Director Kenneth Kaitin. "But developing products that can treat complex diseases is expensive, as it now costs nearly US \$ 2.6 billion to develop and gain marketing approval for a new prescription drug." The Professor of Medicine and Pharmacology sees a trend of drug sponsors looking for the most promising returns on investment transitioning from a high-volume, low-margin business model to a low-volume, high-margin model by directing a growing share of their resources toward development of precision medicines, specialty pharmaceuticals and orphan drugs.

In Switzerland, we have an unusually high concentration of start-ups in life sciences, especially in drug discovery and drug development platforms. An essential link to the Swiss Biotech Ecosystem is the NTN Swiss Biotech ${ }^{\mathrm{TM}}$, which connects public and private players across the entire value chain, with the Swiss Biotech Association representing the interests of the biotech sector, and biotechnet Switzerland offering industrial partners access to the expertise of Swiss universities and research organizations.

\section{Close Partnerships Built on trust}

One example is the longstanding relationship between FHNW Life Sciences and BÜHLMANN Laboratories AG, both near Basel. The SME always stays one step ahead at the international level with medical diagnostic products and kits for use e.g. in inflammation, cellular allergy, neuroimmunology and clinical chemistry. "A key factor for delivering value through innovation was the Commission for Technology and Innovation CTI", comments CEO Dr. Thomas Hafen. The CTI is a state funding agency for innovation in a free market economy. The CTI develops and operates measures to turn untapped scientific innovation potential in Switzerland into value for the economy. "In the customized CTI projects, realized thanks to the University of Basel and the FHNW, we learned how to structure and implement such operations. With the CTI 'Sondermassnahme starker Franken' (special measures for the strong Swiss franc) we initiated our own strategic projects and received a significant contribution to bridge diminished cash flows when the Euro and the USD were rapidly devaluing relative to the Swiss franc in 2011.

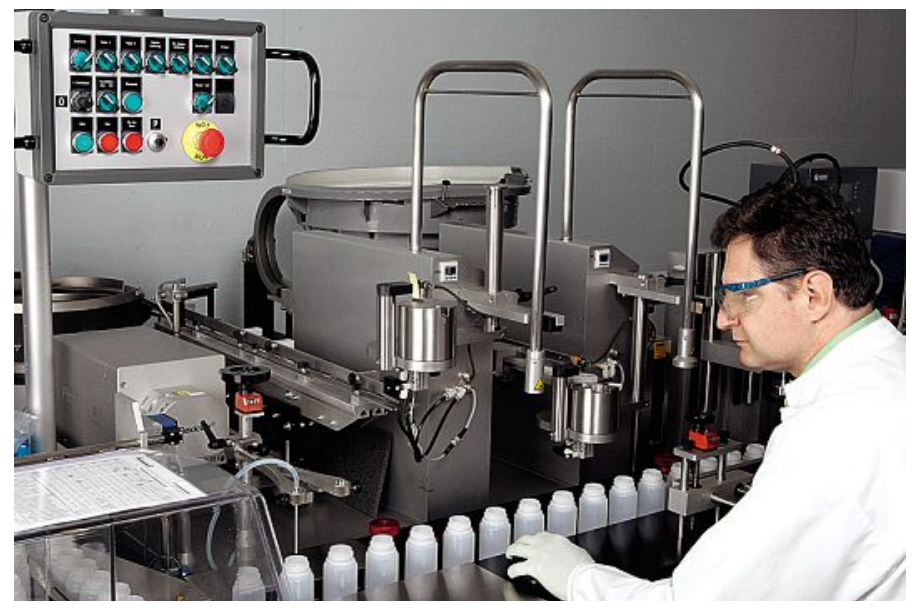

Filling of reagents in the production hall of BÜHLMANN, which offers a broad spectrum of molecular diagnostics products for laboratories of all sizes.

BÜHLMANN Labs are a sound source of innovation. Within the special measures for the strong Swiss franc, the team together with two Swiss companies and the FHNW - created CALEX $^{\circledR}$, a stool extraction device that enables stool extracts to be prepared for biomarker tests outside medical laboratories, e.g. in POC settings or for self-testing (two patents pending). The MIAMI project in the $7^{\text {th }}$ Framework Program with Swiss and European partners generated IBDoc ${ }^{\circledR}$, the first CEIVD marked self-test to help with the therapeutic monitoring of diagnosed IBD patients. A patent protects BÜHLMANN fCAL ${ }^{\circledR}$ turbo, the first turbidimetric calprotectin assay for applications on clinical chemistry platforms, a product resulting from a Eurostar development project. Last but not least, the Quantum Blue $^{\circledR}$ quantitative rapid infliximab Through Level test, the 
first quantitative rapid Therapeutic Drug Monitoring (TDM), is scheduled to be launched at the beginning of 2016 .

\section{Cooperation without Blinkers and Illusions}

But it is an illusion to think that a Swiss SME can turn its back on Europe and focus on new markets in America and Asia. "BÜHLMANN is truly international in its orientation", confirms Thomas Hafen. "Besides the collaborations with non-European partners, European networks are an indispensable part of our strategy." Countries overseas can involve unpredictable risks in terms of cultural and scientific barriers. The complexity and challenges of such projects are significantly higher - for instance with regard to different time zones and language barriers.

The expulsion of Swiss SMEs from the SME specific Horizon 2020 projects is a disaster for the CEO, one that he experienced at first hand: BÜHLMANN has lost two major projects in this biggest ever EU Research and Innovation programme. But no-one seems to care, neither our industry associations nor the relevant departments at federal level or economic development officials. "I cannot believe that we are the only company affected in Switzerland", comments Thomas Hafen with a shake of his head. "The political message is fatal! We should think about what was crucial to our success in the past, namely the European scientific and collaboration networks."

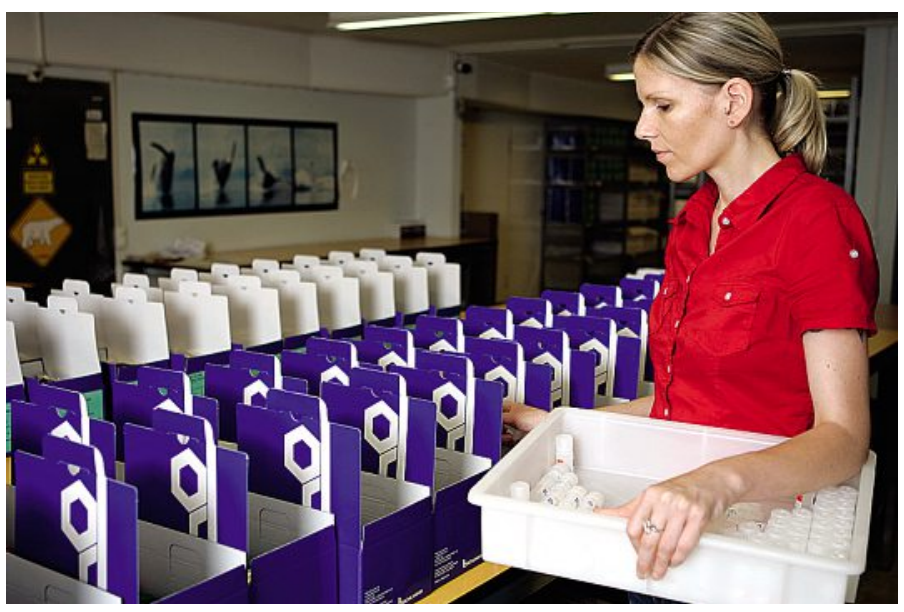

Assembling kits at BÜHLMANN. The company designs, develops, manufactures and sells kits for use in inflammation, cellular allergy, neuroimmunology, clinical chemistry, chronobiology, etc.

\section{It's Red Tape all the way!}

Another cause for concern are the rapidly rising non-tariff trade barriers. "It seems that the more Free Trade Agreements Switzerland signs, the more new barriers are erected at other levels and behind the customs entry point", points out Thomas Hafen. He cites the example of China, where IVD (in vitro diagnostic products) are taxed with a $4 \%$ import tariff. "It is true that these taxes will gradually be reduced. But the exchange rate fluctuations for example are already more important than this tax reduction." What is much more decisive are the new CFDA (China Food and Drug Administration) registration rules, which for example require the inspection of manufacturers outside China. This is a new, unilateral measure, and the requested fee is much higher than all the taxes that we will pay over the next 100 years. To avoid or lower non tariff hurdles is much more difficult than to lower tariffs and there are no easy solutions. A potential pathway should start by mutually recognized international standards, for example: Manufacturers of IVD products must qualify according to ISO 13485 norm as a base of their quality system. "A mutual recognition of ISO certification under the ISO 13485 would be a first step to more harmonized regulation" comments Thomas Hafen. "Mutual agreements on classification of products - so that the same products belong to the same risk categories - would be another step. Harmonized rules for the classification and for the registration of products help manufacturers to avoid uncertainties and to collect necessary data and documentation once."

But that is not all: As Thomas Hafen reports, in Brazil, his company had to struggle for months following the refusal by a customs officer to clear goods shipped from BÜHLMANN Laboratories AG because the company was referred to as BÜHLMANN Switzerland in some of the papers. Obviously, the products were the same. Other countries stipulate that the product boxes must be printed in their national language, or that the precise weight and method of disposal of all product parts is outlined in the papers, etc. "The inventive spirit of administrators is limitless when it comes to building new barriers to stop third country companies from entering their market." The French novelist and playwright Honoré de Balzac hit the nail on the head when he said "Bureaucracy is a giant mechanism operated by pygmies."

\section{Regulation Mania - Death from Asphyxiation}

According to Thomas Hafen, the increasing regulatory requirements are now the fastest growing cost factor in industry - and they are largely underestimated. Gone are the times when a company developed a product, launched it as RUO (for research use only) and acquired clinical experience together with the customer. "That was the business model for BÜHLMANN", states Thomas Hafen. However, with the on-going efforts of the EU to revise the CE-IVD regulations and to establish an 'FDA-like' system, this door is closing. This means that the hurdles for an SME will increase drastically, market entry will be delayed and more expensive. "For the time being, nobody knows how it will actually play out: the IVD regulations are still being negotiated between policy makers and stakeholders." Nowadays, it is crucial for an IVD company to learn as soon as possible how to handle regulatory requirements and to include them from the outset in its feasibility study for a new product. The CEO draws a sad conclusion: "In my experience - and other entrepreneurs share this opinion -, innovation of a new product now costs about $30-40 \%$, but the remaining $60-70 \%$ is on regulatory activities such as paperwork, documentation and bureaucracy."

\section{Now get on your horse - or perish!}

For biotechnet it would be easy to shrug its shoulders and say 'Cobblers, stick to your last', as its only task is to link small, dynamic companies with innovative researchers in future-focused projects. But what is the use of their mutual efforts if the supported SMEs stumble over regulatory issues that are beyond our control? "Biotechnet and the Swiss Biotech Association (SBA) have to move even closer together to effectively tackle innovation - technology development - and regulatory hurdles that stifle innovation”, says Prof. Daniel Gygax, President of Biotechnet Switzerland.

"As a start, we need to develop a more efficient representation of our interests at the national policy level", advises Thomas Hafen. But it looks like our industry associations are not prepared to make common cause and to place a combined effort on their agenda. That's a pity, but probably results from a mixture 

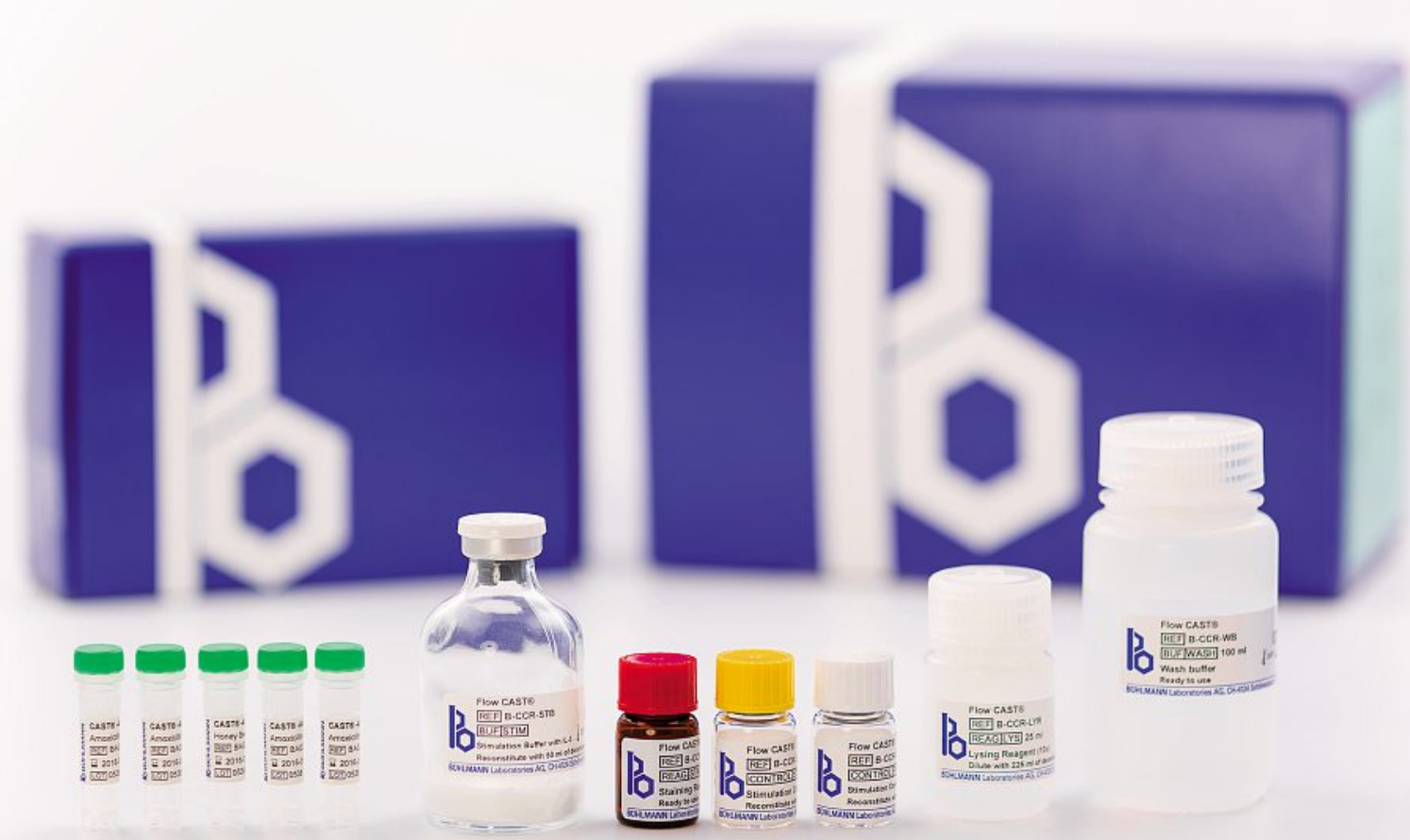

BÜHLMANN Flow CAST ${ }^{\circledR}$ kit is a basophil activation test (BAT) that can be used for the in vitro detection of immediate-type allergic reactions and hypersensitivities to suspected allergens. All illustrations: @ BÜHLMANN

of the lack of political will and economic commitment. However, Daniel Gygax puts it in a nutshell: "In this increasingly difficult market environment our only chance to survive is to cross-link the interests of the whole sector, industrial as well as academic partners, in order to develop strategies and defend our strong position in dealing with our global customers also in the future."
Note: The interviewees have reviewed and accepted all statements made in the interview.

www.biotechnet.ch

www.buhlmannlabs.ch 